\title{
Sobre el incierto futuro del trabajo y del rol de los actores sociales
}

\author{
Daniel Martínez F. Cué*
}

\begin{abstract}
RESUMEN
Existe un cierto consenso en que los cambios tecnológicos producen importantes cambios en la organización de la producción y del trabajo: 1) Los cambios tecnológicos hacen que se destruyan empleos (los costos de oportunidad de incorporar máquinas son ventajosos respecto a los de no reemplazar la mano de obra) pero también que se generen nuevos puestos de trabajo, quedando difícil de prever el saldo neto en cada país, 2) en muchos casos, el efecto de los cambios tecnológicos no es solo la destrucción-creación de empleos, sino la desaparición-creación de tareas y oficios; 3) además de estos efectos cuantitativos, los cambios tecnológicos y la reorganización de las formas de producir dan lugar al surgimiento de nuevas formas no convencionales de utilización del trabajo difíciles de encuadrar en nuestras normativas; 4) se reduce la pobreza de los hogares, pero aumenta la desigualdad en los mercados de trabajo nacionales, así como entre los mercados laborales de los diferentes países. En las páginas que siguen, se analizarán todos estos aspectos. En la sección 2 se sintetizan los efectos cualitativos y cuantitativos de estos cambios sobre el empleo y la composición de la estructura ocupacional, así como las nuevas formas de utilización del trabajo y la creciente desigualdad en el mercado laboral. En la sección 3 se formulan algunas reflexiones sobre los cambios en materia de relaciones laborales y los desafíos que ellos plantean tanto en materia de normativa laboral como en el rol de los actores sociales.
\end{abstract}

Palabras clave: futuro del trabajo, regulación laboral, desigualdad.

Clasificación JEL: F66, J21, J24, J 46, K31

\section{On the Uncertain Future of Work and the Role of Social Actors}

\begin{abstract}
There is some consensus that technological changes bring about important changes in the organization of production and work: 1) technological changes cause job losses (the opportunity costs of incorporating machines are advantageous compared to those of not replacing labor) but also job creation, making it difficult to predict the net balance in each country; 2) in many cases, the effect of technological changes is not only the loss/creation of jobs, but the disappearance/ creation of crafts and trades; 3) besides these quantitative effects, technological changes and the reorganization of forms of production result in the emergence of new, unconventional ways of
\end{abstract}

* Exdirector regional de la OIT para América Latina y el Caribe. 
using labor that are not easily adapted to current regulations; 4) household poverty is reduced, but inequality increases within domestic labor markets, as well as between the labor markets of different countries. This study will analyse all of these aspects. Section 2 summarizes the qualitative and quantitative effects of these changes on employment and the composition of the occupational structure, as well as new ways of using labor and increasing inequality in the labor market. Section 3 presents some reflections on changes in labor relations and the challenges they pose to labor regulations and the role of social actors.

Keywords: Future of work, labor regulation, inequalities

JEL Classification: F66, J21, J24, J 46, K31

\section{INTRODUCCIÓN}

Existe un cierto consenso en que los cambios tecnológicos producen importantes cambios en la organización de la producción y del trabajo, dando lugar a la denominada cuarta revolución industrial, definida esta como «la confluencia y el rápido desarrollo de una amplia gama de tecnologías nuevas, entre ellas la inteligencia artificial, la robótica, la impresión en 3D, el Internet de las cosas, la biotecnología y las cadenas de bloques» ${ }^{1}$.

En lo que se refiere a los efectos de esta cuarta revolución industrial sobre el trabajo y el empleo, también existen algunos consensos. Mencionaré los cuatro que me parecen más importantes: 1) Los cambios tecnológicos hacen que se destruyan empleos (los costos de oportunidad de incorporar máquinas son ventajosos respecto a los de no reemplazar la mano de obra) pero también que se generen nuevos puestos de trabajo, principalmente por la emergencia de nuevos sectores de actividad, en especial en el área de Bioquímica, Computación, Información y Comunicaciones. El saldo neto es difícil de prever en cada país, ya que dependerá de la estructura del sistema productivo, los niveles de educación-formación, el grado de penetración de las nuevas tecnologías, los procesos de urbanización, las migraciones internas y externas, el grado de envejecimiento de la población, el cambio climático, la volatilidad geopolítica, entre otros factores; 2) en muchos casos, el efecto de los cambios tecnológicos no es solo la destrucción-creación de empleos, sino la desaparición-creación de tareas y oficios; 3) además de estos efectos cuantitativos, los cambios tecnológicos y la reorganización de las formas de producir dan lugar al surgimiento de nuevas formas no convencionales de utilización del trabajo como crowfunding, crowdworking, crowdsourcing, etc. En estas nuevas formas de utilización del trabajo no siempre es fácil identificar si existen relaciones laborales y, en caso afirmativo, qué tipo de relación laboral se ha generado; 4) se reduce la pobreza de los hogares, pero

\footnotetext{
1 ADB Group-ADB-BID-EU (African Development Bank-Asian Development Bank-Banco Interamericano de Desarrollo-European Bank). El futuro del trabajo. Perspectivas regionales, 2018 p. 2
} 
aumenta la desigualdad en los mercados de trabajo nacionales, así como entre los mercados laborales de los diferentes países.

En las páginas que siguen, se analizarán todos estos aspectos. En la sección 2 se sintetizan los efectos cualitativos y cuantitativos de estos cambios sobre el empleo y la composición de la estructura ocupacional, así como las nuevas formas de utilización del trabajo y la creciente desigualdad en el mercado laboral. En la sección 3 se formulan algunas reflexiones sobre los cambios en materia de relaciones laborales y los desafíos que ellos plantean tanto en materia de normativa laboral como en el rol de los actores sociales.

Como se podrá apreciar tras la lectura del presente texto, en el mismo no he pretendido profundizar ni en la naturaleza de los cambios tecnológicos actuales, materia de muchos e importantes estudios ya publicados, ni en los efectos de dichos cambios sobre el trabajo y el empleo, ya que sobre esto último no solo existe abundante documentación, sino que, además, el cambio es tan acelerado que la información cuantitativa es extremadamente volátil, al punto que datos publicados hoy día pueden quedar desfasados en los próximos cuatro o cinco meses o contradicha por los resultados de investigaciones posteriores. Si bien todos estos aspectos están tratados en el texto, el énfasis del mismo está puesto en la reflexión sobre el nuevo tipo de relaciones laborales (o comerciales) y en los desafíos que ellos plantea tanto en el ámbito normativo como en el del diálogo social (Sección 3), ya que estos dos temas no han sido objeto de tanto estudio como los anteriores y, además, escasean las propuestas concretas en materia de políticas y normas laborales adecuadas a la cambiante situación del empleo y las relaciones laborales.

Se trata, además, de un texto sin excesivas pretensiones académicas sino más bien de un texto divulgativo para aquellos lectores que no están familiarizados con el tema pero a los que sí les interesa. A aquellos lectores que deseen profundizar en el mismo mediante la lectura de documentos de connotados especialistas les recomiendo dirigirse a la sección de la Comisión Mundial sobre el Futuro del Trabajo de la OIT, (http://www.ilo. org/Search $5 /$ search.do?searchWhat $=$ Comisi $\% C 3 \% B 3 n+$ Mundial+sobre+el+futuro+de $1+$ trabajo\&locale=es_ES).

Debo advertir que con el fin de evitar la sobrecarga gráfica que para marcar la existencia de ambos sexos supondría utilizar en español tanto el grafismo «o/a» como las expresiones «hombres y mujeres», «trabajadores y trabajadoras», etc. se ha optado en este texto por emplear el masculino genérico clásico, en el entendido de que todas las menciones en tal género representan a hombres y mujeres siempre que corresponda. 


\section{2. ¿QUÉ CAMBIOS IMPORTANTES SE ESTÁN PRODUCIENDO EN EL MUNDO DE LA PRODUCCIÓN, EL TRABAJO Y EL EMPLEO?}

\subsection{El CAMbio tecnológico y los CAMbios EN EL MERCADO DE TRABajo}

\subsubsection{Cambios cualitativos en la estructura ocupacional}

Un primer elemento de estos cambios cualitativos es el relativo al desempleo y en especial al desempleo estructural y al denominado «desempleo tecnológico». Generalmente se considera que el desempleo total es contra cíclico en el sentido de que disminuye cuando la actividad económica crece y aumenta cuando el crecimiento es bajo o negativo. El desempleo estructural, por su parte, se considera resultado tanto del tipo de modelo de crecimiento como de la decisión de no trabajar por parte de quienes consideran que no hay puestos de trabajo adecuados o a sus intereses o a sus competencias.

Sin embargo, actualmente se considera que tanto el desempleo total como el desempleo estructural no están determinados en su totalidad por el comportamiento de los ciclos de crecimiento económico, la propia insuficiencia del modelo de crecimiento o la voluntad de las personas, sino que en parte se debe también al efecto de los cambios tecnológicos («desempleo tecnológico»), ya que estos expulsan de sus trabajo a personas de muy baja calificación a las que en muchos casos les resulta imposible reinsertarse en el mercado de trabajo, especialmente por razones de edad además de sus bajas calificaciones (Brynjolfsson y McAfee, 2011). Sin embargo, muchos autores concluyen que si bien no se sabe si la actual cuarta revolución industrial generará desempleo tecnológico, también se sostiene que eso no ocurrió en las revoluciones anteriores, por lo que podría esperarse que ahora tampoco ocurra. Como se señala en una reciente publicación de los Bancos Regionales de Desarrollo (ADB...2018), «Históricamente, el progreso tecnológico no ha creado desempleo tecnológico. Si la historia sirve de referencia, es cierto que las nuevas tecnologías siempre han eliminado algunos puestos de trabajo y han sustituido numerosas tareas que antiguamente eran realizadas por las personas. Sin embargo, también han favorecido la creación de numerosos empleos nuevos impulsados por el aumento de los ingresos y el surgimiento de nuevas ocupaciones» (ADB, 2018, p. 4).

En cuanto al nivel de empleo, hay quienes consideran que el cambio afectará de manera equilibrada a todo tipo de trabajadores, independientemente de sus calificaciones, mientras que otros piensan que afectará especialmente a los empleos que requieren trabajadores con baja calificación (albañiles, ayudantes en estaciones de combustible, personal de limpieza y otros servicios en hospitales, cajeros y cajeras en supermercados, etc.). Esto ocurrirá en especial en los países en desarrollo y en los sectores dedicados a la exportación (Krull, 2016). Hay incluso autores (Ford, 2009) que consideran que las nuevas tecnologías van a afectar relativamente más a los trabajadores con una cualificación media y alta, ya que las tareas más complejas que realizan estos trabajadores podrán en el futuro ser ejecutadas por avanzados programas de computación. 


\section{Como el mismo Krull (2016) señala}

[...] con el cambio tecnológico la mano de obra barata pierde relevancia y las cualificaciones de los trabajadores ganan importancia. Trabajadores con bajos salarios y bajas cualificaciones se sustituyen paso por paso por las nuevas tecnologías en la industria manufacturera y se requieren más trabajadores con medias y altas cualificaciones para mantener y cuidar esos dispositivos de tecnología alta. Esos trabajadores se encuentran más en los países avanzados por lo cual ya hay empresas que reubican la producción a los países de su origen, o en general a los países avanzados (Woolhouse, 2015). Además, la mano de obra barata es cada vez menos barata en comparación con los robots, lo que significa que los costos de oportunidad están a favor de inversiones e incorporación de tecnología en las estructuras productivas (p. 30).

En el sector servicios ocurre lo opuesto a lo del sector manufacturero. Ello se debe a que son servicios que se prestan solo en el mercado local sin competencia externa (no transables) y en el caso de los países en desarrollo la mano de obra que presta esos servicios es más barata de lo que costaría la introducción de equipos y maquinaria que la sustituya.

Sin embargo, los avances de los cambios tecnológicos y su impacto en el empleo de cada uno de los sectores de actividad no necesariamente serán distribuidos de manera uniforme en el mundo, sino que, como señala un reciente informe de los Bancos Regionales de Desarrollo (ADB, 2018), la distribución afectará de manera diferenciada en las distintas regiones del mundo, como consecuencia del diferente peso de cada sector en la estructura productiva de los países de cada región.

Por ejemplo, los avances en la agricultura podrían ser particularmente determinantes en Asia en Desarrollo y África, dado que allí esta actividad representa un mayor porcentaje del empleo. En África, el 51\% de los trabajadores se desempeña en la agricultura, mientras que en Asia la proporción es del 32\%. En las otras regiones, el porcentaje del empleo en la agricultura es mucho menor: solo 16\% en América Latina y el Caribe y 10\% en las economías en desarrollo que son miembros del European Bank for Reconstruction and Development (EBRD). Los avances en las manufacturas, como por ejemplo la robótica y la impresión en 3D, tienen una mayor importancia en las regiones del EBRD3, donde el porcentaje del empleo en este sector es elevado: $30 \%$. Por último, lo que suceda en el sector de los servicios será particularmente determinante para las regiones EBRD y en América Latina y el Caribe, donde este representa cerca del 60\% (ADB, 2018, pp. 13-14).

Para preservar los empleos actuales en la medida de lo posible y, sobre todo, para disponer de la mano de obra calificada necesaria para ocupar los empleos emergentes como resultado de la introducción de nuevas tecnologías, son cruciales las políticas y programas sistémicos de formación y calificación de los trabajadores.

En este marco, es vital proporcionar una educación que prepare para el uso productivo de las nuevas tecnologías, incluido el internet (Grazzi, 2011, p. 46). Para ello se requiere no solo modificar los contenidos de la educación sino también crear el marco institucional adecuado para ello. Avanzar hacia el logro de estos dos objetivos, que en 
muchos países no parecen estar en la mira de las autoridades educativas estatales, son reclamados permanentemente por los gremios empresariales (OIE, 2016) y también por las organizaciones sindicales (CSI, 2017).

En el informe presentado por la organización del World Economic Forum (WEF) de 2016 se señala que

en general, las habilidades sociales — como la persuasión, la inteligencia emocional y la enseñanza de otros - estarán en mayor demanda en todas las industrias que las habilidades técnicas limitadas, como la programación o el funcionamiento y control de los equipos. Habilidades de contenido (que incluyen la alfabetización en TIC y el aprendizaje activo), las habilidades cognitivas (como la creatividad y el razonamiento matemático) y las habilidades de proceso (como la escucha activa y el pensamiento crítico) serán una parte creciente de los requisitos de habilidades básicas para muchas industrias (pp. 26-27)

\subsubsection{Cambios cuantitativos en el nivel y categorías de empleo}

Durante la reunión del World Economic Forum en el año 2016 se divulgaron los resultados de una encuesta realizada por dicha organización sobre los cambios esperados en el empleo durante el período 2015-2020. El WEF extrapoló los datos de la encuesta para estimar el número de empleos creados o perdidos en términos absolutos en todo el mundo en ese período. La encuesta se aplicó a gerentes y managers de grandes empresas de quince grandes economías (Estados Unidos de América, México, Brasil, Reino Unido, Francia, Alemania, Italia, Turquía, países del Consejo de Cooperación del Golfo, Sudáfrica, Japón, China, India, Indonesia, Australia), las mismas que concentran aproximadamente el $65 \%$ de la mano de obra total del mundo.

Los resultados de esta estimación mostraron que en el período analizado se produciría una pérdida neta de más de 5,1 millones de puestos de trabajo, resultantes de una pérdida absoluta de 7,1 millones de empleos — dos tercios de los cuales se concentran en la Oficina y trabajo administrativo - y una ganancia total de 2 millones de empleos (WEF, 2016).

Analizando por familias o tipos de empleo y por sector de actividad o tipo de industria, según la terminología utilizada en EE.UU., se observa lo siguiente a partir de lo declarado por los encuestados. Por familias o categorías de empleo, se esperaban aumentos de los empleos en todos los tipos de familias excepto en los empleos de oficina y administrativos, en el sector de la manufactura, y en la construcción, instalación y mantenimiento. Sin embargo, en las familias en las que se esperaba un aumento del empleo este era poco significativo en el caso de ventas al por mayor y comercio, mientras que los aumentos mayores se operaban en las familias de matemáticas y computación, arquitectura e infraestructura.

Estos resultados se corresponden con las previsiones de la mayoría de los autores de que los cambios tecnológicos provocan una pérdida de empleos en categorías ocupacionales que requieren baja calificación (trabajos de oficia y construcción), así como en la manufactura, donde la penetración de equipos y máquinas que sustituyen 
mano de obra es muy fuerte. Por el contrario, en las familias de empleo que requieren alta calificación, como matemática, computación e infraestructura, es en las que se preveía un mayor crecimiento del empleo.

Cuadro 1. Efecto del empleo de los factores de cambio, por familias de empleo ${ }^{2}, 2015-2020$

\begin{tabular}{lc}
\hline \multicolumn{1}{c}{ Industria / conductor del cambio } & Perspectivas de empleo \\
\hline Computación y matemáticas & $3,21 \%$ \\
Arquitectura e infraestructura & $2,71 \%$ \\
Gerencia & $0,97 \%$ \\
Empleos de oficina y administración & $-4,91 \%$ \\
Ventas y comercio & $0,46 \%$ \\
Manufactura y producción & $-1,63 \%$ \\
Negocios y finanzas & $0,70 \%$ \\
Instalaciones y mantenimiento & $-0,15 \%$ \\
Construcción & $-0,93 \%$ \\
\hline
\end{tabular}

Fuente: WEF (2016, cuadro 4).

Por otra parte, el análisis de los resultados de la encuesta por tipo de industria permitió estimar que, en la opinión de los encuestados, el empleo crecería en todos los tipos de industria excepto en la del cuidado de la salud, si bien el aumento del empleo es muy poco significativo en construcción e infraestructura.

Estos resultados sugieren que las pérdidas de empleo de baja calificación se concentrarán en prácticamente todos los sectores de actividad o tipo de industria, si bien es más significativa en la construcción y los servicios de salud.

Cuadro 2. Efecto empleo de los factores de cambio, por tipo de industria ${ }^{3}$, 2015-2020

\begin{tabular}{lc}
\hline \multicolumn{1}{c}{ Industria / conductor del cambio } & Perspectivas de empleo \\
\hline Construcción e infraestructura & $0,61 \%$ \\
Industria y producción & $1,72 \%$ \\
Energía & $1,54 \%$ \\
Servicios financieros e inversores & $1,54 \%$ \\
Cuidado de la salud & $-0,37 \%$ \\
Tecnología de la información y la comunicación & $2,91 \%$ \\
Medios, entretenimiento e información & $2,31 \%$ \\
Movilidad & $1,61 \%$ \\
Servicios profesionales & $2,45 \%$ \\
\hline
\end{tabular}

Fuente: WEF (2016, cuadro 5). 
Los factores sobre los que se consultaron a los encuestados que podrían ser determinantes para el aumento o reducción del empleo fueron: aumento de la urbanización, crecimiento de la clase media, cambio climático, nuevas fuentes de energía, automatización y robotización, progresos en los procesos de procesamiento de datos, flexibilidad laboral y cambios en las formas de utilización del trabajo, cambio demográfico (aumento de la longevidad), inestabilidad geopolítica. En opinión de los encuestados solo el cambio demográfico (longevidad) y la inestabilidad geopolítica resultan ser factores determinantes en la reducción del empleo, mientas que los demás factores contribuyen al aumento del mismo, salvo la robotización en el caso de la salud y la flexibilización laboral en el caso de los medios de información. Sin embargo, de los factores que contribuyen al aumento del empleo solo el progreso en el procesamiento de datos, la mayor urbanización, el crecimiento de la clase media y las nuevas fuentes de energía se consideraron como factores relevantes para el aumento del empleo, mientras que en los demás factores su relevancia es o poco significativa o irrelevante.

En el informe del WEF (2016, p. 32) se estima también que debido al cambio tecnológico los trabajadores que pierden sus empleos en la manufactura y en la construcción se trasladarán al sector de los servicios y el comercio, lo que obligará a grandes esfuerzos en materia de adaptación de sus competencias laborales y a pesar de ello es posible que más de 3 millones de trabajadores desplazados de la manufactura y construcción corran el riesgo de no conseguir un empleo. El mismo informe señala que

una mejor idea del enorme reto que se deberá asumir en el futuro inmediato, tan solo a nivel de las políticas educativas y de formación profesional, es la predicción de que el $65 \%$ de los menores que están ingresando al sistema educativo accederán a trabajos que no existen en la actualidad y más de un tercio de las competencias básicas demandadas por la mayoría de los empleos (en 2020) estarán compuestas de competencias que hoy todavía no se consideran cruciales para el trabajo.

En este proceso en el que unos sectores se destruye empleo y en otros se crea, la dificultad que se presenta para incorporar a los trabajadores desplazados de unos sectores en puestos de trabajo generados en otros sectores es que, debido a los cambios tecnológicos, la mayor demanda de trabajo en estos sectores demandantes de empleo se dirigirá a personas con las mayores y más sofisticadas capacidades con capacidad para resolver problemas complejos; capacidades que no reúnen la mayoría de los desplazados (Serrano, 2017).

Contrariamente a lo que ocurrirá en la manufactura y construcción, un análisis del tipo de empleos más dinámicos en el futuro realizado por Bensusán (2016) concluye que los empleos con menor riesgo serían la educación, la informática y computación, los medios de comunicación, la gerencia, negocios y finanzas, ingenieros y científicos, nuevos servicios sociales como cuidado de ancianos, etc. En cuanto a la creación de nuevos empleos, estarían los de alto nivel, como analistas de datos, creadores de software y 
aplicaciones, especialistas en redes e inteligencia artificial, diseñadores y productores de máquinas inteligentes. En cambio, en la parte inferior de la escala laboral de nuevos empleos estarían los que capturan datos y otros trabajadores de las plataformas, como los conductores de Uber, cuidadores de mascotas, trabajadores en reparación de objetos del hogar en la economía colaborativa» (p. 33).

Un estudio realizado por la Universidad de Oxford, anterior al del WEF y bastante cuestionado por algunos autores debido a la metodología utilizada, llegó a la conclusión de que el $47 \%$ de los empleos de Estados Unidos podrían ser susceptibles de ser automatizados en una década o dos (lo que no quiere decir que vaya a pasar necesariamente). Por su parte, Frey y Osborne (2013, citados por Krull, 2016) estiman para el mercado laboral de los EE.UU. que 47\% de los empleos puede ser susceptible a la sustitución por nuevas tecnologías. Sin embargo, otros autores como Arntz, Gregory y Zierahn (2016, p. 15) contradicen esta estimación y concluyen que en promedio solo el $9 \%$ de los empleos entre los países integrantes de la Organización para la Cooperación y el Desarrollo Económico (OCDE) son susceptibles por las nuevas tecnologías, siendo su rango de alcance del 6\% (Corea del Sur) a 12\% (Austria, Alemania).

En el ya citado Informe de los Bancos Regionales de Desarrollo (ADB, 2018) se relativizan estas conclusiones sobre el alto grado de automatización futuro. Si bien, señala el documento,

los cálculos iniciales indicaban la existencia de un potencial significativo de automatización, las nuevas estimaciones son menos pesimistas. En estudios más recientes se señala que esas cifras podrían estar sobreestimando las pérdidas potenciales de puestos de trabajo por la vía de la automatización, ya que solo ciertas tareas o actividades dentro de una ocupación son altamente susceptibles a esta. Así pues, con las actuales tecnologías solo un porcentaje relativamente pequeño de empleos (del orden del 5\% al 10\%) puede ser completamente automatizado. De todas maneras, por lo menos el $30 \%$ de las actividades en otro $60 \%$ de las ocupaciones podría ser automatizado con las tecnologías actualmente disponibles (McKinsey Global Institute, 2017b; Armtz, Gregory y Zierahn, 2016). Estas cifras sugieren que si bien algunas ocupaciones desaparecerán, muchas sufrirán una importante transformación en los próximos años. Este es un proceso que ya se ha iniciado [...] Si bien es cierto que las estimaciones iniciales indicaban un mayor potencial de automatización en los países en desarrollo y en los emergentes, cálculos más recientes muestran diferencias más reducidas y ningún patrón claro por nivel de ingreso. El potencial de automatización parecía mayor en las economías en desarrollo [...] .Sin embargo, las nuevas estimaciones indican diferencias mucho menores entre las regiones, y ningún patrón basado en el ingreso. Por ejemplo, según McKinsey (2017a), las economías desarrolladas y África tienen el mismo potencial de automatización. Cabe insistir en que si bien algunas de las cifras iniciales apuntaban a que la automatización podría destruir más de la mitad de los puestos de trabajo existentes, los nuevos cálculos basados en tareas indican que solo el 8\% de los empleos en los países del EBRD (Banco Europeo de Reconstrucción y Desarrollo) y el $9 \%$ en las economías desarrolladas pueden automatizar más del 70\% de sus tareas (p. 6). 
Finalmente, otro aspecto cuantitativo de los efectos de los cambios tecnológicos sobre el empleo es la temporalidad de la permanencia en el empleo. Así, se estima que los miembros de la próxima generación de trabajadores cambiarán de trabajo por lo menos diez veces antes de los cuarenta años, mientras que los negocios en solitario surgirán a un ritmo de alrededor de medio millón al año ${ }^{4}$.

\subsubsection{El cambio tecnológico y la desigualdad en el mercado de trabajo}

En los últimos ańos aumentó el trabajo por cuenta propia, muchos de ellos empleos informales y de menor calidad que los empleos de asalariados, incluidos muchos de los asalariados en empresas informales. Se acentúa así no solo la inutilidad de muchas de las políticas gubernamentales de formalización del empleo informal, sino también una polarización del mercado de trabajo entre empleos informales de baja productividad y empleos formales de una productividad más elevada.

Pero no solo se ha producido en las últimas décadas una mayor polarización en la estructura ocupacional, sino que esta ha ido acompañada de una mayor polarización también en la distribución del capital humano o, si se quiere, entre las personas con más altos niveles de calificación y las que cuentan con los niveles más bajos. Esto se debe no tanto a que los gobiernos hayan reducido la inversión en educación y formación sino a que la inversión privada en educación ha sido mucho mayor que la pública acentuándose la distancia entre una educación privada de mayor calidad y un pública de menor (Cepal y Unesco, 2004). Como señala Krull

Los países de la región han logrado una cobertura educacional más amplia en los últimos ańos, pero el aumento de la cantidad no fue acompańado de un aumento de la calidad. Daude (2013) indica que las estructuras educacionales de la región muestran una baja movilidad social intergeneracional y una calidad deficitaria de la educación, mientras la calidad y el acceso a una educación alta dependen mucho de la clase social. Estas estructuras causan una segmentación entre las escuelas y universidades, las cuales son socioeconómicamente muy homogéneas, y aportan a un mantenimiento de las estructuras de desigualdad. La incorporación de nuevas tecnologías y la expansión de la digitalización en la economía requieren una educación alta y una capacitación permanente para realizar una tarea desafiante no rutinaria y, por lo tanto, para conseguir un empleo de buena calidad. De acuerdo con varias opiniones (Cepal y Unesco, 2004; Daude, 2013; Rubio, 2016), los sistemas presentes de educación todavía no aparecen preparados para cumplir esos desafíos con respecto a dar la oportunidad de lograr altas cualificaciones a mucha gente de todos los estratos sociales. Cabe señalar que en las sociedades con una desigualdad alta y la riqueza muy concentrada — como es el caso en América Latina (ECLAC y Oxfam 2016) - , y donde el nivel de educación depende mucho de los recursos privados, no parece muy probable que el sistema educativo pueda proporcionar una gran cantidad de mano de obra cualificada al mercado laboral. Por lo

4 Diario Expansión. Madrid, junio 2014. 
tanto, una cantidad y calidad limitada de la mano de obra para trabajos con altas cualificaciones puede tener consecuencias para otras áreas, tales como las inversiones o la creación de empleos (2016, p. 32).

$\mathrm{Si}$, además, se toma en cuenta que la trayectoria laboral depende mucho de la educación y formación recibida a lo largo de los años, pero esta a su vez depende en gran medida de la situación socioeconómica de la familia en la que se ha nacido, de modo que los que provienen de familias con mayores recursos accederán a centro educativos de mayor calidad, se pude concluir que si bien la educación-formación contribuye a mejorar la calidad de los empleos a los que se accede a lo largo de la vida, ella no contribuye en igual medida a disminuir la desigualdad en el mercado de trabajo, ya que aunque todos adquieran mayores niveles educativos a lo largo de su vida laboral, los de unos serán más elevados que los de los otros (la «sociedad Sigma» tan bien analizada por Adolfo Figueroa (2003) en sus escritos).

Además de esta desigualdad que podría denominarse «estructural», determinada por la coexistencia y la vinculación entre dos segmentos, formal e informal, con productividades tan distantes, los actuales cambios tecnológicos que caracterizan a la denominada cuarta revolución industrial contribuyen a profundizar el grado de desigualdad en el mercado laboral.

Como se señala en el ya mencionado documento de los Bancos Regionales de Desarrollo (ADB, 2018, p. 5) la nueva ola de automatización podría acentuar aún más la desigualdad, dado que una unidad de trabajo respaldada por las nuevas tecnologías es escalable y se puede vender simultáneamente un número de veces cada vez mayor (por ejemplo, una canción descargada o un programa informático). En cambio, las unidades de trabajo en empleos manuales que no están basados en rutinas, como por ejemplo la limpieza o la preparación por encargo de alimentos y bebidas, se pueden vender una sola vez. Por eso se espera que se siga agudizando la desigualdad en las remuneraciones.

Estos factores están generando una nueva desigualdad al interior del segmento de más alta productividad. Se trata de aquellos trabajadores que, estando altamente calificados y generando altas productividades, trabajan en condiciones de alta precariedad laboral y sin un ingreso mínimo asegurado. El caso más extremo es el de los trabajadores sujetos al denominado "contrato de cero horas» consistente en un acuerdo mediante el cual los trabajadores aceptan estar disponibles para trabajar cuando la empresa contratante lo requiera, pero sin que la misma les garantice ni un mínimo de horas ni de ingresos. En realidad, el trabajador queda «atado» a la empresa pero podría pasarse meses sin trabajar. Sin embargo, las cláusulas de exclusividad incluidas en estos contratos fueron prohibidas en Gran Bretaña (donde se originó esta modalidad de contratación) en el año 2014.

Es cierto que, como muchos laboralistas nos hacen ver, estos contratos a pedido, de servicios externalizados, crowdworking, work on demand, de "cero horas» o similares, si bien son tratados como contratos de tipo comercial en el cual el empleador contrata un servicio o un producto (un nuevo software, por ejemplo), en realidad suelen encubrir 
una relación laboral, ya que entre quien solicita y quien ofrece el trabajo se da la doble condición de «dependencia legal» y «dependencia económica» a que hace referencia María Luz Vega (2017). Sin embargo, por más que se trate de una relación laboral, lo cierto es que cada día más los contratos son individuales, sin fijación de horario ni lugar de trabajo y con pago variable sujeto a resultados y no a la cantidad de horas trabajadas y a las tareas realizadas. Todo ello, además, sin estar sujetos, en muchos casos, a la legislación laboral del país de la persona contratada, quedando esta fuera del radio de acción de la Seguridad Social, de la justicia laboral y de la Inspección del Trabajo de dicho país.

Son varias las causas de esta segmentación "estructural» y de las nuevas manifestaciones de desigualdad en el mercado laboral. Señalaré las cinco que me parecen más importantes. La primera es el modelo de heterogeneidad productiva en el que se ha basado el desarrollo de multitud de países en América Latina y África, que se ha revelado incapaz de generar empleo decente para todos, dando lugar a un excedente de mano de obra que sobrevive en la informalidad.

La segunda es la profundidad del cambio tecnológico que caracteriza la actual cuarta revolución industrial que, como ya mencioné anteriormente, privilegia, en cuanto a condiciones de trabajo y salarios, a los trabajadores altamente calificados y sustituye por equipos automatizados a los trabajadores de menor calificación, a la vez que da lugar a la aparición, en especial en la economía de plataformas, a nuevas formas no convencionales de utilización del trabajo. Si bien la economía de plataformas puede, por ejemplo, generar empleo que beneficie a trabajadores especializados sin necesidad de que estos migren a otros países en busca de un trabajo, también puede contribuir a aumentar la desigualdad en el mercado de trabajo ya que, como se señalan los Bancos Regionales de Desarrollo (ADB, 2018, p. 6),

los empleos en plataforma pueden comprometer aún más el acceso a la seguridad social. En muchos países, los trabajadores por cuenta propia no están obligados a contribuir a ella y rara vez lo hacen voluntariamente, mientras que en otros están obligados por ley, si bien el nivel de control es mínimo. En la medida en que las plataformas aumenten la descentralización del trabajo, así como los contingentes de trabajadores por cuenta propia, la cobertura de salud y de pensiones puede disminuir para un número cada vez mayor de personas.

La tercera causa es el proceso de desregulación del mercado laboral aplicado en muchos países en las dos últimas décadas del siglo pasado y en la presente, en unos casos una desregulación «ligera» y en otras una desregulación «vigorosa» como parte de las políticas de austeridad para enfrentar la crisis económica, como nos recuerda la OIT (2017). Estas desregulaciones no solo se circunscribieron a las relaciones individuales de trabajo (modalidades de contratación, causales de despido, indemnizaciones, etc.) sino que abarcaron también las relaciones colectivas. Como, obviamente se trata de desregulaciones que modifican «a la baja» la normativa laboral y de protección social, uno de sus efectos es que deprimen las condiciones de trabajo y salariales de la mano de obra menos calificada 
en el sector formal, pero sin actuar sobre los trabajadores informales, ya que estos operan al margen de la normativa estatal cualquiera esta sea. La debilidad de la Inspección de Trabajo en muchos países, dificulta, además, controlar que la normativa desreguladora no sea utilizada para precarizar los empleos existentes, desconociendo toda obligación en materia de condiciones de trabajo, seguridad y salud laboral, salarios mínimos, negociación colectiva, etc. En algunos países se ha querido enfrentar esta mayor desigualdad inducida por la desregulación mediante la aplicación a las micro y pequeñas empresas de una «normativa de mínimos», diferente a la normativa general que se aplica a las medianas y grandes empresas. Sin embargo, esta «normativa de mínimos» no ha dado resultados positivos en ninguno de los países en los que ha sido aplicada (OIT-IDRC, 2014).

La cuarta causa es la incipiente promoción de una especie de normativa laboral privada consistente en estándares laborales promovidos por ONG y organizaciones internacionales privadas; normativa que no solo es más laxa que la normativa internacional surgida del seno de la OIT y las normativas nacionales públicas, sino que en algunos casos incluso desconoce aspectos fundamentales de las normas internacionales de la OIT ratificadas por los países (OIT, 2017).

La quinta causa es la búsqueda por parte de las grandes empresas multinacionales de mano de obra barata para trasladar toda o parte de la actividad productiva a las zonas y países en los que se encuentra esa mano de obra. Se produce con ello una profundización del "gap salarial» entre países desarrollados, países emergentes y países en desarrollo agrandando la desigualdad en el mercado de trabajo global.

Zick Srnicek y Alex Williams, dos autores que han estudiado en profundidad el futuro del trabajo, prevén que

en el futuro la desigualdad en el mercado laboral asumirá las características siguientes, entre otras.

i) La precariedad de la clase trabajadora en las economías desarrolladas se intensificará debido al excedente (existente) en el suministro global de mano de obra;

ii) Las recuperaciones sin empleo seguirán haciéndose más profundas y largas y afectarán sobre todo a quienes empleos que puedan automatizarse en ese momento;

iii) Las poblaciones de los barrios pobres seguirán aumentando debido a la automatización del trabajo no especializado en el sector de los servicios;

iv) La marginalidad urbana en las economías desarrolladas aumentará su tamaño a medida que se automaticen los empleos no especializados y mal pagados;

v) El mayor control de los flujos migratorios desde países menos desarrollados a los más desarrollados (2015, p. 152)

\subsection{El CAMbio teCNOLÓgico Y LaS NUEVAS FORMAS NO CONVENCIONALES DE UTILIZACIÓN DEL TRABAJO}

Los cambios operados durante las últimas décadas no se limitan a la pérdida y creación de empleos debido a diferentes factores, principalmente el cambio tecnológico, sino que, 
además, han provocado la aparición de nuevas formas de utilización del trabajo, con lógicas consecuencias sobre el tipo de relaciones laborales tradicionales. Como es usual, la aparición de estas nuevas formas de utilización del trabajo es más acentuada en los países con mayor desarrollo tecnológico y con menor desigualdad social.

Estas nuevas formas de utilización del trabajo son conocidas como crowdsourcing, crowdworking, crowdfunding, work on demand, «economía de plataforma», etc. Como señala Vega,

en la empresa, los modelos organizativos y las formas de trabajo son hoy diferentes. La economía colaborativa aumenta la subcontratación y el outsourcing e implica gestionar los contratos y las condiciones de empleo, así como la organización interna desde una perspectiva diferente que lleva consigo incluso abordar el enfoque transnacional. Las plataformas (intermediarios digitalizados) se convierten en nuevos gestores de la producción y los recursos humanos, (mientras que) los cambios en los equipos de trabajo, la combinación de diferentes relaciones de empleo y contratos, y la forma misma de prestación (a distancia y con horarios absolutamente flexibles) hacen muy distinto el panorama legislativo necesario y aplicable $(2017$, p. 4).

El crowdsourcing (del inglés crowd - multitud-y outsourcing - recursos externos-) se podría traducir al español como colaboración abierta distribuida o externalización abierta de tareas, y consiste en externalizar tareas que, tradicionalmente, realizaban empleados o contratistas, dejándolas a cargo, a través de una convocatoria abierta, de un grupo numeroso de personas que no integran la plantilla estable de la empresas o de empresas proveedoras de servicios, en muchos casos empresas unipersonales.

Jeff Howe, quien acuñó el término en el año 2006, estableció que el concepto de crowdsourcing depende esencialmente del hecho de que, debido a que es una convocatoria abierta, atrae a los más competentes para realizar los trabajos, para actuar eficientemente ante problemas complejos, y para contribuir al desarrollo de la empresa aportando las ideas nuevas y útiles.

Crowdworking, por su parte, consiste en crear espacios en los que profesionales autónomos, teletrabajadores y empresarios trabajan en oficinas comunes en las que comparten sus conocimientos y experiencias. En los croworking, el gestor se dedica a conectar y crear oportunidades profesionales y personales para sus miembros.

Los crowdworking promueven la aparición de ideas y soluciones que se están desarrollando lejos de las grandes ciudades gracias a las alianzas con socios que ya tienen programas de emprendimiento a nivel local. Los crowd workers, entre los que, según Krull (Cepal 2016), predominan las mujeres (54\%) y los jóvenes (51\%) tienen un producto que es su mano de obra y para ocuparla buscan permanentemente que esta sea demandada por alguna empresa que opera en el ramo o sector en el que el crowd worker tiene competencias. Un estudio en el Reino Unido de Huws y Joyce (2016) citado por Krull (Cepal, 2016, p. 15) mostró que «más de un quinto ya ha buscado por lo menos una vez un trabajo a través de una plataforma de Internet, mientras más de uno de cada 
diez personas ya ha encontrado un trabajo así. Los ingresos de tal trabajo forman la parte principal de todos los ingresos para un tercio de estos crowd workers».

Por su parte, el crowdfunding o micromecenazgo consiste en la financiación colectiva a través de internet. Se trata de una cooperación entre un grupo de personas para conseguir dinero (u otros recursos), aunando esfuerzos e iniciativas de otras personas u organizaciones.

El crowsourcing, el crowdworker y el crowdfunding son el núcleo de las nuevas formas de utilización del trabajo.

Es interesante la discusión sobre el concepto de economía colaborativa. Se dice que el concepto es equivocado, porque no refleja otra cosa que la extensión de un mecanismo de mercado que impacta en las relaciones laborales. Por ello, algunos autores como Drahokoupil y Fabo (2016, p. 2) citados por Bensusán (2016, p. 39) proponen en su lugar

el concepto de «economía de plataforma» entendido como «el uso de plataformas en línea que disminuyen el costo de transacción de la subcontratación y el acceso temporal a bienes y servicios».......Se caracterizan por tres aspectos: la plataforma provee un algoritmo que enlaza a los proveedores del servicio y los usuarios, reduce costos de transacción a través de micro transacciones y provee servicios para reducir el riesgo involucrado en las transacciones de mercado....incluyendo la reputación y sistemas de monitoreo así como mecanismos de aseguramiento estándar y servicios legales contra el fraude».

Para evitar controles estatales y ciertas barreras de entrada como impuestos y gravámenes, estas plataformas pueden operar informalmente. Como señala Bensusán (2016) básicamente existen tres tipos de plataformas: i) las que posibilitan acceder a bienes o servicios (caso del sistema de alquileres de Airbnb) producidos o prestados por trabajadores autoempleados; familias, etc. En este caso es extremadamente difícil determinar si existe algún tipo de relación laboral entre el que compra el bien y quien lo produce o quien demanda un servicio o lo presta. Generalmente se considera que en este caso existe una relación comercial pero no laboral estrictamente; ii) las plataformas que operan de manera organizada en mercados locales bien prestando servicios no prestados por otros (caso del sistema de alquiler de coches sin conductor - Car2Go-) o prestados por otros pero con características y condiciones diferentes a las de estos últimos (caso sistema de taxis Uber), bien intercambiando bienes (nuevas economías colaborativas); iii) plataformas que brindan acceso a trabajos de mediana o alta calificación.

Como acabo de señalar, en el caso de crowdworking los trabajadores no tienen un contrato de trabajo sino que son trabajadores autoempleados e independientes que venden un producto o servicio generado por ellos mismos. La ventaja del sistema crowdworking en el caso de las empresas es que las ayuda a reducir costos, fundamentalmente bajando y deprimiendo los salarios pagados por la empresa (Brabham, 2008, pp. 76-78), mientras que para los crowd workers es la forma de obtener ingresos. 
Si bien la economía colaborativa y crowdsourcing están vinculados a la digitalización de la economía y a la expansión de las TIC, no se debería, como señala Krull,

mezclar los dos si bien tienen algunos elementos en común. Mientras la economía colaborativa es un modelo de hacer negocios, crowdsorcing es una forma de la organización del proceso de trabajo y está también aplicada por empresas de la economía tradicional. $\mathrm{Al}$ inicio, la economía colaborativa fue considerada como un proyecto idealista para compartir cosas, fortalecer comunidades y, también, reducir el consumo y la huella de carbono. Pero después de poco tiempo la economía colaborativa se ha convertido en una máquina de crear empresas y generar ganancias gracias a las nuevas tecnologías y las plataformas de Internet (Scholz, 2016, p. 1). Ahora se la usa principalmente para ofrecer servicios (por ejemplo, Handy, TaskRabbit o Uber) o para compartir productos de una manera comercial (por ejemplo Airbnb o Getaround)» (2016, cap. II, p. 15).

Ahora bien, aun cuando estamos hablando de nuevas formas de organización del trabajo, algunas de ellas no son tan nuevas como pareciera, ya que corresponden a algunas de las formas de lo que tradicionalmente se ha denominado empleo atípico. Un reciente informe de la OIT (2016e) clasifica cuatro distintas formas de empleo atípico, y en ellas se pueden identificar algunas modalidades de crowdworking y crowdsorcing.

\section{Cuadro 3. Las distintas formas de empleo atípico}

1. EMPLEO TEMPORAL. Contratos de duración determinada, como los contratos basados en proyectos o tareas; trabajo estacional; trabajo ocasional, incluido el trabajo por días. NO ES UN EMPLEO DE DURACIÓN INDEFINIDA.

2. TRABAJO A TIEMPO PARCIAL Y A PEDIDO. Horas de trabajo normal más reducidas que las equivalentes a tiempo completo; empleo a tiempo parcial marginal; trabajo a pedido, incluidos los contratos de cero horas. NO ES UN EMPLEO A TIEMPO COMPLETO

3. RELACIÓN DE TRABAJO MULTIPARTITA. También conocida como 'cesión temporal', 'intermediación' y 'alquiler de mano de obra'. Trabajo temporal por medio de agencia y prestación de servicios en régimen de subcontración. RELACION NO DIRECTA NI SUBORDINADA CON EL USUARIO FINAL

4. EMPLEO ENCUBIERTO O POR CUENTA PROPIA ECONÓMICAMENTE DEPENDIENTE Empleo encubierto, empleo por cuenta propia económicamente dependiente, empleo por cuenta propia falso o clasificado. NO ES PARTE DE LA RELACION DE TRABAJO

Fuente: OIT. El empleo atípico en el mundo. Retos y perspectivas, 2016 (Gráfico 1).

En este mismo informe de la OIT (2016e) se señala que

cuando los trabajadores no están contratados directamente por la empresa en la que prestan sus servicios, participan en relaciones de trabajo multipartitas, como sucede cuando el trabajador es asignado a un lugar de trabajo y pagado por una agencia de trabajo temporal, pero el trabajo se realiza para una empresa usuaria. En la mayoría de los países, el contrato o la relación de trabajo se establece entre la agencia y el trabajador, 
mientras que lo que vincula a la agencia y la empresa usuaria es un contrato comercial. Por lo general, se considera que no existe una relación de trabajo entre los trabajadores cedidos por las agencias de trabajo temporal y las empresas usuarias; sin embargo, en ciertas jurisdicciones se imponen obligaciones jurídicas a las empresas usuarias con respecto a estos trabajadores, especialmente en lo concerniente a la salud y la seguridad [...]. Además, algunas relaciones de trabajo pueden ser ambiguas cuando los respectivos derechos y obligaciones de las partes interesadas no están claramente definidos, o cuando existen vacíos o insuficiencias en la legislación, inclusive con respecto a la interpretación o la aplicación de las disposiciones jurídicas. Un ámbito que a veces carece de claridad jurídica es el del empleo por cuenta propia económicamente dependiente, según el cual los trabajadores prestan servicios a una empresa en virtud de un contrato comercial pero sus ingresos dependen de uno o unos cuantos clientes, de quienes reciben instrucciones directas sobre la forma en que deben realizar el trabajo. Por lo general, estos trabajadores no están cubiertos por las disposiciones de la legislación laboral o la seguridad social basada en el empleo, aunque algunos países han adoptado disposiciones específicas para garantizarles algunas protecciones (p. 3).

\section{LAS GRANDES CUESTIONES A DEBATIR SOBRE EL FUTURO DEL TRABAJO: DESIGUALDAD EN EL EMPLEO Y LOS INGRESOS, REGULACIÓN DE LA RELACIÓN LABORAL, ROL DE LOS ACTORES SOCIALES}

Mirando hacia el futuro, mi opinión es que nuestra prioridad no debería limitarse a debatir sobre los factores que causan los cambios en el mundo del trabajo ni sobre la cuantificación de esos cambios ya que, justamente por ser cambios, se modifican constantemente y, además, son cuestiones sobre las que se ha analizado y escrito mucho. Ello no quiere decir que ambas cuestiones deban ser dejadas de lado. En modo alguno, la Academia debe seguir atenta a la aparición de nuevos factores de cambio y a las transformaciones cualitativas y cuantitativas provocadas por dichos cambios. Lo que en mi opinión se necesita con urgencia es profundizar además nuestro análisis y debatir nuevas propuestas respecto a cuatro cuestiones que pareciera que no son suficientemente debatidas y que, sin embargo, resultan cruciales para el futuro de trabajo: la desigualdad en el mercado de trabajo, las «nuevas» relaciones de trabajo, los desafíos que enfrentan los actores sociales y el diálogo social.

\subsection{LA LUCHA CONTRA LA DESIGUALDAD EN EL MERCADO DE TRABAJO}

El aumento del excedente estructural de mano de obra al que me he referido en la sección anterior se comienza a producir después de la primera guerra mundial, al compás del desarrollo de la gran industria capitalista y de las masivas migraciones desde el campo a las ciudades con el consecuente proceso de progresiva urbanización, de desarrollo de 
barrios pobres y de una mayor marginalidad urbana; aspectos todos ellos que ya fueron analizados por Lewis (1954) hacia la mitad del siglo pasado. Sin embargo, en las dos décadas finales del pasado milenio, en un marco de políticas de fuerte desregulación de los mercados, se agudizó la precarización de la estructura ocupacional y «explotaron» las migraciones por razones económicas, no ya del campo a la ciudad (proceso que se ralentiza y en algunos países se estanca) sino entre países con diferentes niveles de desarrollo.

En este contexto, nada hace pensar que ni la automatización ni la robotización, por más que contribuyen a generar nuevos tipos de empleo tendrán la capacidad de generar buenos empleos para la totalidad de la mano de obra excedentaria, sino que, por el contrario, los procesos de segmentación y de desigualdad en el mercado laboral tenderán a profundizarse.

Para enfrentar este futuro de desigualdad y mayor segmentación es sabido, y nadie suele discutirlo, que la educación y la formación técnico profesional desempeñan un papel medular. Sin embargo, también es sabido que con educación y formación no basta. Como señala Morgan (2014, p. 54), citado por Alejandro Melamed (2017): «el mundo está cambiando tan rápido que para el momento en que los nuevos estudiantes terciarios se gradúen, mucho de lo que hayan aprendido será irrelevante y en muchos casos obsoleto. Esto significa que el conocimiento y la experiencia no son más el commodity principal».

¿Qué más debería hacerse, a nivel de políticas públicas y privadas, para acompañar los esfuerzos que se hagan en materia de capacitación y formación técnico profesional, para progresivamente cerrar la mencionada brecha? Es muy poco lo que se debate a este respecto.

Como señalé en un artículo reciente (Martínez, 2016), el futuro del trabajo, tal como ha sido examinado a lo largo de este texto, lleva a considerar seriamente la necesidad de establecer un sistema de ingreso mínimo universal o, lo que en mi opinión es más conveniente, de Renta Mínima de Inserción, a fin de que la creciente desigualdad en el mercado de trabajo no conduzca a muchos trabajadores al desempleo, el subempleo y la pobreza.

La renta básica universal planteada en 1995 por Van Parijs y otros intelectuales europeos, se define como el derecho de todo ciudadano o residente en un país a percibir periódicamente del Estado una cantidad de dinero que le sirva para, cuando menos, atender las necesidades básicas sin que se le exija a cambio contraprestación alguna. Esta renta, al ser universal, podría otorgársele a cada persona desde el momento de su nacimiento y el sistema sería financiado por el régimen general de impuestos que el Estado recauda de la ciudadanía. En el caso de quienes ya perciben un ingreso, el sistema de renta básica estaría asociado al régimen de impuesto a la renta o ingresos de cada persona, entendiendo por ello que actuaría como un impuesto negativo (un descuento impositivo o desgravamen parcial) que variaría en función de los ingresos adicionales de cada ciudadano. 
La renta minima de inserción o salario social (ver Rojo Torrecilla y García Nieto, 1989; Cepal, 2014), por su parte, consiste en una ayuda a quienes están en situación de pobreza, o en riesgo de caer en ella, y que no disponen de los ingresos mínimos necesarios para satisfacer sus necesidades básicas (alimentación, vivienda, transporte, especialmente). Habitualmente es una prestación de naturaleza económica, compuesta de un monto fijo y otro variable en función de la cantidad de miembros de la familia. Sin embargo, en algunas ocasiones y en algunos países, la contribución también puede ser en especie (sobre todo alimentos) o en exoneraciones de pago, total o parcial, de determinados servicios públicos como luz y agua.

Bajo diferentes denominaciones, este sistema de renta mínima de inserción opera en muchos países del mundo. En América Latina opera en Argentina («Prestaciones familiares» desde 1953 y «Asignación universal por hijo» desde 2009), en Bolivia («Prestaciones familiares» desde 1956, «Bono Juancito Pinto» desde 2008), en Brasil («Salario familiar» desde 1963 y «Programa de garantía de renta mínima» desde 1991), en Colombia («Asignaciones familiares» 1957), en Costa Rica («Asignaciones familiares» desde 1975) y en Uruguay («Asignaciones familiares» desde 1943), por citar solo algunos casos.

En un reciente informe de la OIT, en el marco de la Iniciativas sobre el Futuro del Trabajo (ILO 2017f) se señala que

para gestionar la transición (entre la actualidad y el futuro próximo en lo que al trabajo se refiere) también existe la posibilidad de reemplazar el ingreso perdido con un ingreso universal, a menudo denominado «ingreso ciudadano» o «ingreso básico universal»..... Si bien muchos defienden que esta medida devaluaría el trabajo, en realidad liberaría a las personas de la necesidad de ganarse la vida y les brindaría la posibilidad de decidir cuánto quieren trabajar, algo que históricamente solo podía decidir una minoría privilegiada. Una versión más reciente del ingreso ciudadano implica brindar a todos los ciudadanos una parte del crecimiento de la economía. Según este concepto, los individuos son accionistas de la economía y su trabajo es una «acción» cuyo valor es superior a sus salarios. Para concretizar esta propuesta, se podría considerar la creación de bancos nacionales de inversión capitalizados por los contribuyentes con fondos de fiscalidad general y con el mandato de realizar inversiones que generen tasas de rendimiento privadas y sociales. Dichas tasas podrían, por un lado, ser objeto de nuevas inversiones, y, por otro, ser distribuidas como pagos de dividendos. La necesidad de realizar una inversión pública de este tipo se ha exacerbado en años recientes debido a la financiarización de la economía real y a la avidez de ingresos a mediano plazo de los inversores. Si bien algunos apoyan la idea de un ingreso básico universal debido a la incertidumbre sobre la cantidad de empleos disponibles en una economía cada vez más digital, quedan preguntas por resolver sobre su financiamiento. Un esquema de este tipo podría ser financiado, por ejemplo, con elevadas tasas marginales de imposición al ingreso y a la sucesión, pues, además de facilitar la transición a una semana de trabajo más corta, el principal objetivo sería democratizar la distribución de la riqueza (pp. 6 y 7). 
Dado que el objetivo de estas medidas es aportar ingresos para quienes quedan desplazados del mercado de trabajo como consecuencia de los cambios tecnológicos y, por edad o nivel de calificación, tienen dificultades para reinsertarse en el mismo, considero que en este caso la Renta Mínima de Inserción es más conveniente que la Renta Básica Universal, ya que está específicamente orientada al objetivo de apoyar a los desplazados.

\subsection{LAS «NUEVAS» RELACIONES LABORALES}

La segunda cuestión que requiere un debate urgente es la referida a las relaciones laborales en el futuro y a la regulación, nacional e internacional, de las mismas.

Como ya mencioné anteriormente, las nuevas tecnologías tienden a atomizar e individualizar las relaciones de trabajo. Más en concreto, en las nuevas formas no convencionales de la utilización del trabajo, la extensión de la jornada laboral, el horario de trabajo, el salario y las condiciones de trabajo son fijadas y determinadas por el propio trabajador, y no por el empleador/contratista. Como señala Park (2016) el trabajador ya no piensa en compañeros de trabajo sino en competidores; y siente que solo él es responsable por el resultado de su trabajo. De hecho, al momento de elaborar este texto tuve la oportunidad de revisar un contrato de servicios entre un técnico residente en un país sudamericano y una empresa situada en un país árabe, que contiene doce cláusulas. La primera refiere al propósito del acuerdo entre las partes, de la 2 a la 9 se establecen los compromisos del técnico en relación a la confidencialidad de la información que recibirá de la empresa contratante, la cláusula 10 refiere a la duración del acuerdo, la número 11 fija el acuerdo de las partes con el contenido de las cláusulas anteriores, anulándose cualquier compromiso anterior, y en la 12 y última se establece que cualquier diferendo entra las partes será resuelto en las Cortes de Gran Bretańa y de acuerdo a las leyes británicas. No hay en todo el acuerdo o contrato una sola referencia a aspectos laborales tales como jornada de trabajo, condiciones laborales, salario, etc. etc.

Por su parte, en las empresas han cambiado tanto los modelos organizativos como las formas de trabajo, pudiendo externalizarse tareas y trabajo no solo fuera de la empresa sino incluso fuera del país y del propio continente en el que está situada la empresa contratista, lo que plantea grandes desafíos al tipo de legislación y regulación laboral que debiera aplicarse.

Sin embargo, estas condiciones, independientemente de las particularidades que asumen en cada país, no son fácilmente perceptibles en las nuevas formas de trabajo externalizado, transnacionalizado, a pedido o a demanda, crowdworking, plataformas, etc. Es por ello que, como mencioné anteriormente, las nuevas formas no convencionales de utilización del trabajo operan fuera del marco de las relaciones colectivas (sindicalización, convenios sindicato-patronal, etc.) y en ellas el trabajador goza de una autonomía casi plena para fijar las condiciones de trabajo, e incluso hay trabajadores cuyos contratos estén sometidos a una autoridad que puede quedar establecida en un 
país muy diferente al del oferente y al demandante del trabajo o servicio. Son todos ellos trabajos en los que los empleadores no asumen responsabilidad laboral alguna, si bien monitorean constantemente el avance del trabajo. Es cada vez más común que una empresa de un país europeo u oriental contrate a un técnico que reside en un país latinoamericano y que ese contrato establezca que cualquier diferendo entre las partes será resulto por las cortes de Bermudas o Bahamas, por poner un ejemplo. Se trata, en última instancia, de trabajos en los que el tradicional desbalance de poder entre el empleador y el trabajador (de ahí la necesidad de la regulación), se ha modificado, si bien el empleador o contratante puede dar finalizado el contrato en cualquier momento sin necesidad de justificación alguna y sin que se considere un despido sino solo una ruptura de un contrato considerado no laboral.

Además, es frecuente también que el trabajador colabore con otros trabajadores situados en diferentes lugares, formando un equipo que tiene como único objetivo obtener el resultado que el contratante ha solicitado (crowdworking). De hecho, es frecuente que un trabajador, en colaboración con otros, realice trabajos para varias empresas a la vez, sin una relación de dependencia jerarquiza respecto de ninguna de ellas.

La principal diferencia entre esta modalidad de trabajo (crodworkers) y la de trabajadores "por demanda", es que estos últimos operan utilizando una aplicación o plataforma digital que es manejada por una empresa (la que los contrata), como es el caso de Uber, mientras que los primeros lo hacen trabajando en línea utilizando cualquier aplicación disponible en internet.

Es preciso tener en cuenta que se trata de actividades que no son ilegales. Los trabajadores declaran sus ingresos y pagas los correspondientes impuestos y es muy probable que muchos de ellos contribuyan también a la Seguridad Social. De lo que se trata es de empleos con alta autonomía, sin horario de trabajo, por resultado, con condiciones de trabajo autodeterminadas por el trabajador, etc. en los que la relación laboral es muy difusa y en ocasiones (como cuando contratante y el contratado son de y están en países diferentes) difícilmente perceptible.

La expansión de este fenómeno de contrataciones crowdsorcing, croworking o work on demand no quiere decir que los empleos tradicionales (asalariados públicos y privados) desaparecerán, pero su proporción en el conjunto de los ocupados será cada vez menor. En la actualidad, según el mencionado informe de la OIT (2017f) la relación de trabajo «típica» solo abarca al $29 \%$ de la población mundial empleada. Por el contrario, los empleos en los que la relación laboral o es tenue o es difícilmente perceptible son cada vez más abundantes y su proporción es cada vez mayor (el $71 \%$ del empleo mundial según la OIT).

El exponencial aumento de estas modalidades de trabajo en las últimas décadas ha generado un amplio debate sobre, primero, si se trata de nuevas modalidades de relaciones laborales y, segundo, en el supuesto de que sí lo sean, cómo regularlas, ya que las regulaciones de la relación de trabajo clásica no parecen adecuarse a las características de 
estas nuevas modalidades. ¿Existe una relación laboral o no? ¿En el futuro primarán las relaciones laborales reguladas por los códigos de trabajo nacionales y las normas de la OIT o estas serán sustituidas por relaciones de prestación de servicios personales, comerciales o mercantiles, reguladas por el Código Civil y las leyes mercantiles y de sociedades? ¿Si se considerase que existe relación laboral, cómo se aplica la normativa laboral? ¿Habrá una regulación laboral para los empleos clásicos de duración indefinida y otra regulación, o ninguna, para algunos tipos de empleos atípicos y para las nuevas formas no convencionales de utilización del trabajo? Si el contratante y el contratado están en países diferentes ¿se aplica la legislación laboral de qué país? ¿Cuál es la autoridad laboral que intervendría en caso de conflicto entre el contratante y el contratado? De igual modo, ¿cómo se aplican las normas de la OIT?, ¿cómo se aplican los convenios Internacionales relativos a la jornada de trabajo, salario justo, condiciones de trabajo, etc.?

Algunos países han comenzado a legislar normas que regulan la relación laboral en estas nuevas firmas de utilización del trabajo. Se trata especialmente de ciertas regulaciones en el campo del teletrabajo. En América Latina, México legisló a mediados de la década pasada que la actividad realizada a distancia utilizando tecnologías de información y comunicación debe ser considerada como trabajo. Antes ya se había legislado en el mismo sentido en Brasil (con relación a los accidentes de trabajo), Colombia y Chile.

Por otra parte, la OIT menciona en un reciente documento (OIT, 2017), que las demandas individuales y colectivas presentadas por los sindicatos han insistido en que los trabajadores de las plataformas son en realidad empleados de quienes los contratan, y hay algunos pocos tribunales en los que los jueces les han dado la razón como el caso de los trabajadores de taxis de New York Alliance. Sin embargo, esta reacción sindical ni es generalizada ni parece estar modificando la situación global en esta materia.

Como afirma María Luz Vega (2017),

desde el punto de vista del ordenamiento, el problema central [...] es determinar en este entramado de contratos y relaciones, la existencia de una verdadera relación laboral, considerada desde el precepto de la primacía de la realidad, como promueve la Recomendación 198 de la OIT; es decir definir y caracterizar la forma en la que prestación se realiza y no el mero acuerdo formal suscrito que puede ser opuesto a la realidad de la prestación [...] Las condiciones que determinan si una prestación laboral constituye una relación de trabajo son muy diferentes de un país a otro, y algunas veces la ley asigna diferentes significados a cada término, acompanándolo de un calificativo distinto, por ejemplo «subordinación legal» $\mathrm{y}$ «dependencia económica». La «subordinación legal» define el hecho de que el empleador o su representante, dirigen o es probable que dirijan la realización del trabajo. Se considera «dependencia económica» cuando la suma recibida por el trabajador constituye su única fuente de ingresos, siendo la cantidad abonada por una persona o empresa en función der la actividad laboral realizada, y/o cuando el trabajador no es independiente económicamente y está vinculado económicamente a la esfera de actividad en la que opera la persona o empresa que puede ser considerada como empleador (p. 6). 
El debate sobre como debiera ser estas regulaciones ya ha superado los límites de la universidad y los «laboralistas» de cada país y ha hecho que la propia Organización del Trabajo (OIT) cree un grupo especial (Comisión Mundial sobre el Futuro del Trabajo) para el estudio del fenómeno y la formulación de propuestas.

Si bien la única información de la que dispongo sobre qué propuestas se están analizando en el seno de esta Comisión Mundial es la contenida en el Inception Report for the Global Commission on the Future of Work de 2017, mi opinión es que cualesquiera sean las propuestas que se formulen esta deberían considerar los siguientes siete temas centrales dadas las nuevas condiciones en las que opera el mercado de trabajo como consecuencia de los cambios tecnológicos en curso:

a) Un nuevo tipo de contrato laboral que considere las particularidades de las «nuevas» relaciones de trabajo ya mencionadas. Este nuevo tipo de contrato, además de establecer explícitamente la existencia de una relación laboral entre contratado y contratante, permitiría acordar la flexibilidad de la duración de la jornada de trabajo, ya que en las «nuevas» formas de utilización del trabajo la jornada de las ocho horas, y la normativa al respecto, no tienen mucho sentido, así como la protección social de la que gozaría el trabajador contratado. Con una orientación similar a la aquí planteada, un grupo de expertos convocados por la OIT (ILO 2017g, p. 3) ha propuesto «un contrato de trabajo único que eliminaría la distinción entre contratos permanentes y temporales y aumentaría el nivel de protección del trabajador con antigüedad (Casale y Perulli, 2014). La finalidad de este enfoque es abordar el fenómeno de la segmentación del mercado de trabajo entre trabajadores permanentes («agentes internos») y trabajadores temporales («agentes externos»).

b) El establecimiento de un piso mínimo de protección social cualquiera sea el tipo de empleo y modalidad de trabajo, así como adecuadas condiciones de trabajo, en especial las relacionadas con la seguridad y salud de los trabajadores y trabajadoras. Para ello, revisten especial importancia la recomendación 202 adoptada por la OIT en el año 2012 sobre un "piso mínimo» de protección social", en especial las garantías establecidas en el artículo 5 de dicha Recomendación relacionadas con las personas adultas:

Los pisos de protección social mencionados en el párrafo 4 deberían comprender por lo menos las siguientes garantías básicas de seguridad social: a) acceso a un conjunto de bienes y servicios definido a nivel nacional, que constituyen la atención de salud esencial, incluida la atención de la maternidad, que cumpla los criterios de disponibilidad, accesibilidad, aceptabilidad y calidad; ....... c) seguridad básica del ingreso, por lo menos equivalente a un nivel mínimo definido en el plano nacional, para las personas

5 OIT. The Social Protection Floors Recommendation (No. 202), adopted 2012 
en edad activa que no puedan obtener ingresos suficientes, en particular en caso de enfermedad, desempleo, maternidad e invalidez, y d) seguridad básica del ingreso para las personas de edad, por lo menos equivalente a un nivel mínimo definido en el plano nacional.

c) La negociación colectiva, sea por sector, por rama o por empresa; Esta negociación tanto cuando esté circunscrita al ámbito nacional como cuando tenga aplicación transnacional (negociación entre sindicatos internacionales y una empresa o grupo de empresas) debiera garantizar, como mínimo, los Derechos Fundamentales en el Trabajo establecidos en la Declaración de la OIT de 1998: libertad de asociación y negociación colectiva, prohibición del trabajo forzado y de menores, no discriminación, además de otros derechos relacionados con la seguridad laboral y la salud, asegurando que el crowdworking en los países en desarrollo se realice en adecuadas condiciones de trabajo.

d) El adecuado control de la «normativa laboral privada» (en especial los códigos de conducta de las empresas y algunos estándares laborales internacionales establecidos fuera del ámbito de la OIT), así como la adecuación de la misma a los Convenios Internacionales de la OIT ratificados por los países. En materia de control normativo debiera, además, debatirse seriamente y en profundidad la consecuencia de las limitaciones que, desde su creación, ha tenido la OIT para controlar la aplicación de las Normas Internacionales de Trabajo al carecer de poder sancionatorio, más allá de la «sanciones morales» que impone la Comisión de Expertos y el Comité de Libertad Sindical. En este sentido, ¿es conveniente continuar con una OIT «sin dientes» o habría que plantearse si no es conveniente establecer algún tipo de capacidad sancionatoria efectiva, por más que muchos señalen que es la «falta de dientes» lo que ha permitido la sobrevivencia y la relevancia de la OIT?

e) Un compromiso serio y decido por parte de los Estados de fortalecer las Administraciones de Trabajo nacionales, en especial las Inspecciones de Trabajo.

\subsection{LOS DESAFÍOS QUE ENFRENTAN LOS ACTORES SOCIALES}

La tercera cuestión que se requiere debatir está relacionada con los actores sociales. Si en el futuro se incrementasen sensiblemente los empleos en los que la relación laboral es individual y muy difusa en cuanto que no aplica, en todo o en parte, la normativa laboral nacional e internacional, en ese caso las tasas de afiliación sindical tenderían a bajar (en muchos países oscilan actualmente entre un 3\% y un 6\%) y el movimiento sindical se debilitaría gravemente, reduciéndose a la representación de una fracción, mayor o menor, de los asalariados privados y en algunos países también de los funcionarios públicos. 
A este respecto, en el ya citado Informe de la OIT en el marco de la Iniciativa sobre el Futuro del Trabajo (OIT, 2017f, p. 9) se señala que

la erosión del empleo tradicional también supone un desafío para el papel de los sindicatos. La desaparición/invisibilidad del empleador debilita aún más la posición de los sindicatos, quienes pierden a su contraparte. En el actual debate sobre el futuro del trabajo, se criticó también a los sindicatos por fungir como una herramienta del siglo XX, por ser únicamente aptos para la relación de empleo típica y por ser obsoletos en términos de su capacidad de proteger a los trabajadores en el mundo cambiante del empleo del siglo XXI y, en particular, en la economía digital. Durante el debate se señaló que los sindicatos han luchado con éxito porque se normalice el trabajo, y se considera que podrán hacerlo nuevamente hoy en día y en el futuro. Pese a que suelen enfrentarse a un entorno hostil, los sindicatos ya han empezado a organizar a los trabajadores que forman parte de las cadenas mundiales de suministro, a los trabajadores por cuenta propia y a aquellos que trabajan en la economía digital (por ejemplo, en el sector de los medios de comunicación). Además, constituyen aún la voz más importante de los trabajadores. Por ello, debilitar el poder de los sindicatos podría tener consecuencias económicas, sociales y políticas negativas para los trabajadores y para la sociedad en general. En un contexto en el que las desigualdades son cada vez más marcadas en todo el mundo y ante la aparición de nuevas formas de trabajo, es importante contar con un proceso democrático de diálogo entre los trabajadores y los empleadores para mediar en el control de los beneficios de la producción.

En este contexto, los gremios empresariales perderían interés por el tripartismo y acabarían orientando su actividad a la defensa de los intereses económicos y corporativos de las empresas y no tanto a la negociación con los sindicatos y, mucho menos, a la participación en procesos de diálogo social.

El Inception Report for the Global Commission on the Future of Work de la OIT del año 2017 dedica buena parte del análisis a la situación de la sindicalización de los trabajadores y agremiación de los empleadores. En el caso de los trabajadores el informe reconoce un descenso de la sindicalización en la mayoría de los países (no en todos) si bien los sindicatos siguen siendo en su conjunto la mayor organización de la sociedad civil del mundo, y la Confederación Sindical Internacional (CSI) representa a la importante cifra de 181 millones de trabajadores. Además, señala el Informe, en muchos países la acción sindical y la asociación sindical se está extendiendo hacia los trabajadores informales como es el caso del Informal Traders Alliance de Sudáfrica.

En el caso de los empleadores, el mismo informe de la OIT (2017h) reconoce el debilitamiento de los gremios que los agrupan debido en parte a que las grandes empresas, en especial las transnacionales, tienden a operar "por fuera" de las organizaciones gremiales empresariales, mientras que las pymes, que conforman el grueso de los agremiados, tienen una alta heterogeneidad e incluso intereses divergentes entre ellas. Sin embargo, como se recoge en el Informe de la OIT, «en Europa occidental, organizaciones de 
empleadores y asociaciones empresariales están adaptando su estructura organizacional así como sus actividades a las necesidades cambiantes de sus asociados. Una adaptación similar está en curso en otras partes del mundo» (43). Algunas organizaciones de empleadores alemanas incluso están aplicando una política de no comprometer a los nuevos asociados con las obligaciones de los convenios colectivos firmados por la organización antes de su afiliación.

Quizás el futuro de las organizaciones de los actores sociales sea más halagüeño que lo que sugiero en los párrafos anteriores, sin embargo el riesgo de una «des-sindicalización» progresiva y acentuada existe, al punto que algunas centrales sindicales (desde la Confederación Sindical Internacional hasta centrales nacionales como el PIT-CNT de Uruguay) han reiterado la necesidad de que el movimiento sindical analice esta situación y adopte medidas en defensa de la organización sindical; medidas que incluirían el reconocimiento de la necesidad de nuevas formas de regulación de la relación laboral.

Lo mismo ocurre en el gremialismo empresarial, observándose en algunos países un proceso de mayor coordinación intergremial, creándose confederaciones que integran y coordinan a todas o a la mayoría de las organizaciones empresariales nacionales.

\subsection{EL DIÁLOGO SOCIAL EN LA CUARTA REVOLUCIÓN INDUSTRIAL}

El diálogo social tripartito es, sin duda, una de las instituciones laborales más importantes en el mundo en los últimos cien ańos. De hecho todas las Normas Internacionales del Trabajo son producto del diálogo social tripartito y, en consecuencia, toda la legislación laboral de los diferentes países del mundo, que se orientan por esa normativa internacional es producto del tripartismo.

Sin embargo, el diálogo social tripartito no pasa por un buen momento desde hace dos décadas o más. Si bien la OIT defiende la importancia que ha tenido el tripartismo en la solución de las crisis de los últimos veinte años, como serían la crisis del petróleo, la crisis financiera asiática o la crisis recesiva de los años 2008-2009 (OIT, 2017h), lo cierto es que en el apogeo de las políticas de fuerte desregulación de los mercados de la segunda mitad de la década de 1980 y durante la de 1990 no solo no hubo procesos de diálogo social importantes, sino que más bien en una mayoría de los países no hubo diálogo social tripartito de ningún tipo.

Varias son las razones de ese debilitamiento del diálogo social. En primer lugar, el desinterés de muchos Gobiernos y gremios empresariales por el diálogo habida cuenta de que todos ellos defendían y promovían ese tipo de políticas económicas y sociales desreguladoras. En segundo lugar, el ya mencionado debilitamiento del movimiento sindical y su limitada capacidad de movilización y de defensa de políticas no flexibilizadoras ni de desprotección en el campo social y laboral. En tercer lugar, la propia debilidad de la OIT cuya dirección no fue capaz a fines del siglo pasado y primera década del presente siglo de proponer serias alternativas técnicas y políticas a sus países miembros y que se 
limitó a destinar importantes recursos a la elaboración y difusión de rimbombantes pero inútiles Declaraciones sobre la gobernabilidad de la globalización.

Lamentablemente, el futuro inmediato del diálogo social tripartito tampoco parece ser del todo halagüeńo. A la ya mencionada debilidad de las organizaciones sindicales y empresariales, se une, por una parte el extraordinario desarrollo de muy dinámicas organizaciones de la sociedad civil que, sin formar parte del tripartismo, conducen las grandes luchas mundiales en materia de derechos como son las organizaciones que actúan en el campo de los derechos humanos, de la lucha contra la discriminación por motivos de género, de apoyo a los más pobres y a los refugiados, a los niños, etc.

Por otra parte, la persistencia de la informalidad y el surgimiento de nuevas formas no convencionales de utilización del trabajo, fuera del marco de los convenios colectivos y sin que los trabajadores involucrados tengan organización y vinculación sindical, hace que una gran parte de la población trabajadora no integre el entramado sindical y, por tanto, el tripartismo.

La propia OIT (2017 h) reconoce esta problemática y plantea, como una posible solución, que «es probable que la solución residirá en dar forma a un nuevo consenso político sobre la gobernanza del trabajo, a nivel global. Ello deberá ir acompañado de esfuerzos para tomar en cuenta los puntos de vista e intereses de otros actores que [...] pueden jugar un papel en la búsqueda de la justicia social» (44).

¿Qué se puede hacer para fortalecer el diálogo social tanto a nivel nacional como global? Obviamente no tengo respuestas concluyentes. Sin embargo, creo que para intentar fortalecer el diálogo deben explorarse nuevos caminos que vayan más allá del tradicional y acotado diálogo tripartido. Para ello, es necesario volver a considerar la conveniencia y la operatividad de lo que década atrás se llamó el «tripartismo plus», el que no prosperó debido a las reticencias tanto de las organizaciones de empleadores como de trabajadores, que aceptaban a otras organizaciones como observadoras en los procesos de diálogo pero nunca como actores del mismo. También es importante desarrollar una institucionalidad específica, o adaptar la existente, para que los acuerdos a los que se arribe mediante el diálogo social tengan la fuerza jurídica y política necesaria que garantice su aplicación. La Corte Interamericana de Derechos Humanos es un ejemplo del tipo de institución a la que me estoy refiriendo.

En todo caso, en tanto se logran avances en la recuperación de un diálogo social genuino en los diferentes países, es imprescindible avanzar en fortalecer lo que ya existe: las organizaciones de trabajadores y empleadores, el tripartismo clásico y el diálogo social, en especial el que se lleva a cabo en el seno de la OIT y que ha dado a luz toda la normativa laboral internacional existente, por más que este se revele hoy día como insuficiente y en algunos aspectos no adaptada a la nueva realidad laboral que los actuales cambios tecnológicos generan. 


\subsection{A MODO DE CONCLUSIÓN}

$\mathrm{Al}$ inicio de este texto señalé que existen ciertos consensos acerca de los efectos de los cambios tecnológicos actuales sobre el mundo del trabajo. Así, si bien se destruye empleo en algunos sectores, también se genera en otros, con un saldo neto que dependerá de la composición de la estructura productiva de cada país, de los niveles de educaciónformación, de las migraciones, de la volatilidad geopolítica, entre otros.

A estos consensos se deben añadir otros que surgen del texto. Uno de ellos es que producto de los cambios tecnológicos y de la reorganización de procesos productivos, surgen nuevas formas de utilización del trabajo y en ellas las relaciones laborales o no existen (aparentemente) o son muy difusas. Otro consenso es que la normativa laboral tradicional no contemple adecuadamente el tipo de relación laboral que se desarrolla en estas nuevas formas de utilización del trabajo, por más que se quiera enmascarar dicha relación laboral, y que por ello es necesario adecuar y desarrollar la normativa laboral existente para que se pueda aplicar a estas nuevas formas de trabajo. Un consenso más es el reconocimiento del debilitamiento en las últimas décadas de la organización sindical de los trabajadores y de la gremial de empleadores de muchos países, lo que ha contribuido, además del desinterés de muchos gobiernos y empresarios, al debilitamiento, y en muchos casos desaparición, de los procesos de diálogo y concertación social. Adicionalmente a estos consensos señalados, también hay acuerdo entre académicos, políticos y dirigentes sindicales y empresariales en que los actuales sistemas de educación y formación, si bien han servido para extender la cobertura de la educación, en especial la educación pública, adolece de unos problemas de calidad que hace que no esté contribuyendo adecuadamente a preparar a las personas para trabajos y empleos que, cada vez más, demandarán no solo una alta especialización sino también una gran capacidad de resolución de problemas.

Tomando en cuenta estos consensos básicos se pueden formular algunas líneas estratégicas en lo que a las políticas laborales para el futuro se refiere, en especial en América Latina donde todos los consensos que acabo de señalar son aplicables.

En primer lugar, es preciso insistir en la necesidad de una profunda revisión de los sistemas de educación y formación a fin de que puedan responder adecuadamente a las auténticas demandas provenientes de la actividad productiva.

En segundo lugar, es necesaria una adecuación de la normativa laboral; adecuación que no solo reconozca la existencia de la relación laboral en las nuevas formas de utilización del trabajo, sino también que regule dicha relación, protegiendo los derechos laborales del trabajador así como los derechos económicos del empleador.

En tercer lugar, es urgente defender agresivamente la libertad sindical y fomentar la organización de los trabajadores, persiguiendo sin contemplaciones toda forma de hostigamiento y persecución sindical, incluida la organización por parte de algunos empresarios de sindicatos fantasmas supeditados a los dictados de esos empresarios. 
Finalmente, es económica, social y políticamente importante fomentar los procesos de Diálogo y Concertación Social, todo ello en el marco de un nuevo «contrato social» que, tal como propusieron hace siglos Locke, Hobbes y Rousseau, establezca e institucionalicen mecanismos democráticos que faciliten arribar a acuerdos que no solo protejan derechos y establezcan obligaciones de las partes, sino también que garanticen la libertad, la justicia social y el progreso económico individual y colectivo. Se trata, en suma, de volver a algo tan evidente y a la vez sencillo como es el acuerdo, contrato o pacto que sume, frente al desacuerdo y el conflicto que resten.

\section{REFERENCIAS BIBLIOGRÁFICAS}

ADB Group ADB-BID-EU (African Development Bank-Asian Development Bank-Banco Interamericano de Desarrollo-European Bank) (2018). El futuro del trabajo. Perspectivas Regionales. Washington. Disponible en https://publications.iadb.org/bitstream/handle/ 11319/8840/El-futuro-del-trabajo-Perspectivas-regionales.pdf?sequence=3\&isAllowed=y

Apella, Ignacio y Gonzalo Zunino (2017). Cambio tecnológico y el mercado de trabajo en Argentina y Uruguay. Un análisis desde el enfoque de tareas. Serie de informes técnicos del Banco Mundial en Argentina, Paraguay y Uruguay, $\mathrm{n}^{\circ}$ 11. Washington, D.C.: Banco Mundial. Disponible en http://documents.worldbank.org/curated/ en/940501496692186828/Cambio-Tecnológico-y-Mercado-de-Trabajo-en-Argentinay-Uruguay-Un-Análisis-desde-el-Enfoque-de-Tareas

Arntz, Melanie, Terry Gregory y Ulrich Zierahn (2016). The Risk of Automation for Jobs in OECD countries: A comparative Analysis, OECD, Social, Employment and Migration Working Papers No 189, París: OECD Publishing.

Autor, David H. (2015). Why are there still so many jobs? The History and future of workplace automation. Journal of Economic Perspectives, 29(3), 3-30.

Banco Mundial (2016). Digital Dividends. World Development Report 2016. Washington, DC. Bensusán, Graciela (2016). Nuevas tendencias en el empleo: retos y opciones para las regulaciones y políticas del mercado de trabajo. Versión preliminar. Santiago de Chile: Cepal.

Bonekamp, Linda y Matthias Sure (2015). Consequences of Industry 4.0 on human labour on work organization. Journal of Business and Media Psychology, 6(1), 33-40

Bowles, Jeremy (2014). The Computarisation of European Jobs. Bruselas: Bruegel.

Brabham, Daren C. (2008). Crowdsorcing as a model for problem solving: an introduction and cases. The International Journal of Research into New Media Technologies, 14(1), 75-90. https://doi.org/10.1177/1354856507084420

Brynjolfsson, E. y A. McAfee (2014). The second machine age: Work, progress, and prosperity in a time of brilliant technologies. Nueva York: W. W. Norton \& Company.

Byrne, David M., John G. Fernald y Marshall B. Reinsdorf (2016). Does the United States have a productivity slowdown or a measurement problem. Finance and Economics Discussion Series 2016-017. Washington, D.C.: Federal Reserve Board.

Cepal (2014). Programas de renta minima vinculada a la educación: las becas escolares en Brasil.

Codagnone, Cristiano, Fabienne Abadie y Federico Biagi (2016). The Future of Work in the 'Sharing Economy'.Market Efficiency and Equitable Opportunities or Unfair Precarisation. European Commission.

CSI (2017). El futuro del trabajo. Bruselas: Confederación Sindical Internacional. 
De Stefano, Valerio (2016). The rise of the 'just-in-time workforce': On-demand work, crowdwork and labour protection in the 'gigeconomy'. Ginebra: ILO.

Drahokoupil, Jan y Brian Fabo (2016). The platform economy and the disruption of the employment relationship, Policy Brief N $N^{\circ}$ /2016 European Economic, Employment and Social Policy, European Trade Union Institute, Bruselas.

Elliot, Stuart (2014). Anticipating a Luddite Revival. Issues in Science and Technology 30(3), 27-36.

Federal Ministry of Labour and Social Affaires (2015). Green Paper, Work 4.0 Germany.

Federal Ministry of Labour and Social Affaires (2016). Re-Imagining Work. White Paper, Work 4.0 Germany.

Figueroa, Adolfo (2003). La sociedad sigma: una teoría del desarrollo económico. Lima: Fondo Editorial de la Pontificia Universidad Católica del Perú y Fondo de Cultura Económica.

Frey, C. B. y M. A. Osborne (2013). The future of employment: How susceptible are jobs to computerisation? Working Paper $\mathrm{N}^{\circ}$ 7, Oxford Martin School, University of Oxford.

Hayter, Susan (2015). El futuro incierto de las relaciones laborales. Revista Internacional del Trabajo (OIT), 134(1), 1-4.

Howe, Jeff (2006). «Crowdsorcing: A definition» Crowdsorcing. http://www.crowdsorcing.com

ILO (International Labour Organization) (1998). Declaración de la OIT relativa a los principios y derechos fundamentales en el trabajo. Ginebra: ILO.

ILO (International Labour Organization) (2012) Procesos de autoreforma sindical en las Américas. Avances del Grupo de Trabajo sobre Autoreforma Sindical (GTAS) en 2011-2012. ILOACTRAV-CSA.

ILO (International Labour Organization) (2012) The Social Protection Floors Recommendation ( ${ }^{\circ}$ 202). Ginebra.

ILO (International Labour Organization) (2014). OIT-IDRC. Foro sobre «Formalización de la Informalidad - Aportes de la academia». Informe de relatoría. Lima, Perú.

ILO (International Labour Organization) (2016a). Non-Standard Employment around the World: Understanding challenges, shaping prospects, Ginebra.

ILO (International Labour Organization) (2016b). Social contract and the future of work: Inequality, income secutirty, labour relations and social dialogue, Future of Work Issue Notes Series $\mathrm{N}^{\circ}$ 4. Ginebra: ILO.

ILO (International Labour Organization) (2016c). A Challenging Future for the Employment Relationship: Time for affirmation or alternatives? Future of Work Serie $N^{\circ} 3$. Ginebra: ILO (forthcoming).

ILO (International Labour Organization) (2016d). Technological changes and work in the future: Making technology work for all. Ginebra: ILO.

ILO (International Labour Organization) (2016e). El empleo atípico en el mundo. Retos y perspectivas. Ginebra: ILO.

ILO (International Labour Organization) (2017f). El futuro del trabajo que queremos: un diálogo global. Ginebra: ILO.

ILO (International Labour Organization) (2017g). Un futuro lleno de retos para las relaciones de trabajo ¿Es momento de consolidar o de buscar alternativas? Ginebra: ILO.

ILO (International Labour Organization) (2017h). Inception Report for the Global Commission on the Future of Work. Ginebra: ILO.

ILO (International Labour Organization) (2017i) Universal Social Protection Floors: Costing Estimates and Affordability in 57 Lower Income Countries. Ginebra: ILO. 
Krull, Sebastian (2016). El cambio tecnológico y el nuevo contexto del empleo. Tendencias generales y en América Latina. Santiago de Chile: Cepal.

Lakhani, Tashlin, Sarosh Kuruvilla y Ariel Avgar (2013). From the Firm to the Network: Global Value Chains and Employment Relations Theory. British Journal of Industrial Relations, 51(3). https://doi.org/10.1111/bjir.12015

Leimeister, Jan M., Shkodran Zogaj, David Durward e Ivo Blohm (2015). Crowdsourcing und Crowd Work - Neue Formen digitaler Arbeit. En Angelika C. Bullinger (ed.), Mensch 2020 transdisziplinäre Perspektiven (pp. 119-124). Chemnitz: Verlag aw\&I Wissenschaft und Praxis.

Lewis, W. Arthur (1954). Economic Development with Unlimited Supplies of Labour. The Manchester School of Economic and Social, 22(2), 139-191. https://doi.org/10.1111/ j.1467-9957.1954.tb00021.x

Martínez, D. (2016). Cómo estabilizar el nivel de empleo durante la contracción de la actividad económica. Un debate pendiente en América Latina. Economía, XXXIX(77), 253-263. https://doi.org/10.18800/economia.201601.007

McKinsey Global Institute (2015). A Labor Market that Works: Connecting Talent with Opportunity in the Digital Age. McKinsey\&Company. Disponible en https://www.mckinsey.com/ //media/ McKinsey/Featured\%20Insights/Employment\%20and\%20Growth/Connecting\%20 talent\%20with\%20opportunity\%20in\%20the\%20digital\%20age/MGI\%20Online\%20 talent_A_Labor_Market_That_Works_Executive_\%20summary_June\%202015.ashx

Melamed, Alejandro (2017). El futuro del trabajo y el trabajo del futuro. Buenos Aires: Planeta.

Mokyr, Joel, Chris Vickers y Nicolas Ziebarth (2015). The history of technological anxiety and the future of economic growth: Is this time different? Journal of Economic Perspectives, 29(3), 31-50. https://doi.org/10.1257/jep.29.3.31

Morgan, Jacob (2014). The Future of work. Attract talent, build better leaders and create a competitive organization. Hoboken, NJ: Wiley.

Nübler, I., V. Kümmritz, S. Rubínová (2016, forthcoming). GVCs and economic complexity-a comparative analysis of China, South East Asia and Latin America, Working paper. Ginebra: ILO, Research Department.

OIE (2016). Empleo y crecimiento. Eslabones y desafíos. Ginebra: Organización Internacional de Empleadores. Disponible en http://www.ioe-emp.org/fileadmin/ioe_documents/ publications/Policy\%20Areas/employment/ES/_2016-04-26__Documento_de_posicion_de_la_OIE_-_Trabajo_y_crecimiento.pdf

Park, J. (2016). Role and principles of Labor law to regulate new employment relations; with focus on digital platform work. En Research on the Changes in Employment Relations and Social Welfare Paradigm. Chapter 7. Korea Labor Institute.

Rifkin, Jeremy (1995). The End of Work: The Decline of the Global Labor Force and the Dawn of the Post-Market Era. Nueva York, NY: Putnam Publishing Group.

Rojo Torrecilla, Eduard y García Nieto (1989). lucha contra la pobreza y cambio social: renta mínima garantizada y salario ciudadano. Madrid: Cáritas Española.

Ryder, Guy (2015). Predicting the Unpredictable - The Future of Work. Speech on the occasion of the First Annual Global Employers' Summit in Bahrain. October 2015.

Serrano, Jordi (2017). El futuro del trabajo. http://blog.futurodeltrabajo.com/

Srnicek, Nick y Alex Williams (2015). Inventing the Future: Postcapitalism and a World Without Work. Brooklyn, NY: Verso.

Sundararajan, Arun (2014). What Airbnb Gets About Culture that Uber Doesn't. Harvard Bussines Review. Disponible en https://hbr.org/2014/11/what-airbnb-gets-about-culturethat-uber-doesnt 
Susskind, Richard y Daniel Susskind (2015). The Future of the Professions. Oxford: Oxford University Press.

Triguero Martínez, Luis Ángel (2016). La influencia del entorno crowd sobre las relaciones de trabajo y sus protagonistas: crowdworking y crowdworkers. Labour and Law Issues, 2(2), 80-108.

Vega Ruiz, María Luz (2015). El futuro del trabajo: ¿revolución industrial y tecnológica o crisis del estado social? Ginebra: OIT.

WEF (2016). The Future of Jobs Employment, Skills and Workforce Strategy for the Fourth Industrial Revolution. Davos, Suiza. Disponible en http://www3.weforum.org/docs/WEF_Future_ of_Jobs.pdf

Weller, Jurgen y Claudia Roethlisberger (2011). La calidad del empleo en América Latina. Macroeconomía del Desarrollo Series LC/L.3320-P, No. 110. Santiago de Chile: Cepal.

Woolhouse, Megan (2015). Some offshored manufacturing jobs return to US. The Boston Globe. Disponible en http://www.bostonglobe.com/business/2015/07/26/som

Documento recibido el 28 de mayo de 2018

y aceptado el 1 de julio de 2018 